\title{
Correction \\ Correction: Kinchin, I.; Doran, C.M. The Cost of Youth Suicide in Australia. Int. J. Environ. Res. Public Health 2018, 15, 672
}

\author{
Irina Kinchin 1,2,*(D) and Christopher M. Doran ${ }^{1}$ \\ 1 Centre for Indigenous Health Equity Research, School of Health, Medical and Applied Sciences, \\ Central Queensland University, Brisbane 4000, Australia; c.doran@cqu.edu.au \\ 2 The Cairns Institute, James Cook University, Cairns 4870, Australia \\ * Correspondence: i.kinchin@cqu.edu.au; Tel.: +61-7-3023-4114
}

Received: 27 June 2018; Accepted: 2 July 2018; Published: 6 September 2018

The authors wish to add the following corrections to their paper published in the International Journal of Environmental Research and Public Health [1]. When computing Total Indirect Cost column in Table 4, Indirect Cost per single youth suicide was multiplied by Total Years of Productive Life Lost (YPLL). The correct calculation should have been Indirect Cost per single youth suicide multiplied by Total Number of Suicides (not YPLL). This led to an overestimated Total Indirect Cost and Total Cost of Youth Suicide in Australia reported in the paper. Following further suggestion by a reviewer, we aligned the wording under Sections 3.2 and 3.3 (i.e., Productivity Loss and Bereavement) with the terms used in tables (i.e., Indirect Cost and Intangible Cost).

In the abstract, the sentence regarding the Total Cost should be as follows: The total economic loss of youth suicide in Australia is estimated at \$511 million a year (equivalent to US\$ 352 million), ranging from $\$ 460$ to $\$ 586$ million. Abstract should read as follows.

Abstract: Suicide is the leading cause of death among Australians between 15 and 24 years of age. This study seeks to estimate the economic cost of youth suicide (15-24 years old) for Australia using 2014 as a reference year. The main outcome measure is monetized burden of youth suicide. Costs, in 2014 AU\$, are measured and valued as direct costs, such as coronial inquiry, police, ambulance, and funeral expenses; indirect costs, such as lost economic productivity; and intangible costs, such as bereavement. In 2014, 307 young Australians lost their lives to suicide ( 82 females and 225 males). The average age at time of death was 20.4 years, representing an average loss of 62 years of life and close to 46 years of productive capacity. The average cost per youth suicide is valued at $\$ 2,884,426$, including $\$ 9721$ in direct costs, $\$ 2,788,245$ as the value of lost productivity, and $\$ 86,460$ as the cost of bereavement. The total economic loss of youth suicide in Australia is estimated at \$511 million a year (equivalent to US\$352 million), ranging from $\$ 460$ to $\$ 586$ million. These findings can assist decision-makers understand the magnitude of adverse outcomes associated with youth suicide and the potential benefits to be achieved by investing in effective suicide prevention strategies.

Results should read as follows:

\section{Results}

\subsection{Economic Cost of a Single Youth Suicide}

Table 3 displays the consequences of a single youth suicide by age and sex. The indirect cost as the loss of economic productivity attributable to each suicide averaged $\$ 2.8$ million in 2014 dollars, ranging from \$1.9 million for females aged 20-24 to \$3.2 million for males aged 15-19. The intangible cost represented by the average cost of bereavement was estimated at $\$ 86,460$. The direct economic cost per suicide was $\$ 9721$. 
Table 3. The economic cost of a single youth suicide, Australia, 2014, by age and sex.

\begin{tabular}{ccccccc}
\hline \multirow{2}{*}{ Variable } & \multirow{2}{*}{$\begin{array}{c}\text { Years of } \\
\text { Life Lost }\end{array}$} & $\begin{array}{c}\text { Year of Productive } \\
\text { Life Lost }\end{array}$ & \multicolumn{3}{c}{ Economic Cost (AU\$) } & \multirow{2}{*}{ Total } \\
\cline { 5 - 6 } & & & Direct & Indirect & Intangible & \\
\hline Age 15-19 & & & & & & \\
\hline Female & 67.5 & 49.0 & $\$ 9721$ & $\$ 2,156,865$ & $\$ 86,460$ & $\$ 2,253,046$ \\
Male & 63.0 & 48.6 & $\$ 9721$ & $\$ 3,225,873$ & $\$ 86,460$ & $\$ 3,322,054$ \\
Person & 65.2 & 48.7 & $\$ 9721$ & $\$ 2,962,760$ & $\$ 86,460$ & $\$ 3,058,941$ \\
\hline Age 20-24 & & & & & & \\
\hline Female & 62.2 & 43.7 & $\$ 9721$ & $\$ 1,944,958$ & $\$ 86,460$ & $\$ 2,041,139$ \\
Male & 58.3 & 43.9 & $\$ 9721$ & $\$ 2,908,937$ & $\$ 86,460$ & $\$ 3,005,118$ \\
Person & 60.2 & 43.8 & $\$ 9721$ & $\$ 2,671,674$ & $\$ 86,460$ & $\$ 2,767,855$ \\
\hline Age 15-24 & & & & & & \\
\hline Female & 64.2 & 45.7 & $\$ 9721$ & $\$ 2,029,820$ & $\$ 86,460$ & $\$ 2,126,001$ \\
Male & 59.9 & 45.5 & $\$ 9721$ & $\$ 3,035,860$ & $\$ 86,460$ & $\$ 3,132,041$ \\
Persons & 62.1 & 45.6 & $\$ 9721$ & $\$ 2,788,245$ & $\$ 86,460$ & $\$ 2,884,426$ \\
\hline
\end{tabular}

\subsection{Total Economic Cost of Youth Suicide}

The total economic cost of youth suicide in Australia was estimated at \$511.1 million (in 2014 AU\$) per year, of which the indirect cost was the largest cost accounting for $94 \%$ (Table 4). The amount of indirect costs was estimated at $\$ 481.6$ million. The cost of bereavement (intangible cost) was the second largest cost of \$26.5 million. Direct costs accounted for just under \$3 million.

Table 4. The total economic cost of youth suicide, Australia, 2014, by age and sex.

\begin{tabular}{|c|c|c|c|c|c|c|}
\hline \multirow{2}{*}{ Variable } & \multirow{2}{*}{$\begin{array}{c}\text { Years of } \\
\text { Life Lost }{ }^{1}\end{array}$} & \multirow{2}{*}{$\begin{array}{l}\text { Year of Productive } \\
\quad \text { Life Lost }{ }^{1}\end{array}$} & \multicolumn{3}{|c|}{ Economic Cost (AU\$) } & \multirow{2}{*}{ Total } \\
\hline & & & Direct & Indirect & Intangible & \\
\hline \multicolumn{7}{|l|}{ Age 15-19 } \\
\hline Female & 2159 & 882 & $\$ 311,057$ & $\$ 38,830,479$ & $\$ 2,766,720$ & $\$ 41,908,256$ \\
\hline Male & 4849 & 2104 & $\$ 748,482$ & $\$ 139,745,447$ & $\$ 6,657,420$ & $\$ 147,151,349$ \\
\hline Person & 7008 & 2986 & $\$ 1,059,539$ & $\$ 181,686,489$ & $\$ 9,424,140$ & $\$ 192,170,168$ \\
\hline \multicolumn{7}{|l|}{ Age 20-24 } \\
\hline Female & 3108 & 1228 & $\$ 486,027$ & $\$ 54,711,657$ & $\$ 4,323,000$ & $\$ 59,520,684$ \\
\hline Male & 8628 & 3655 & $\$ 1,438,641$ & $\$ 242,212,052$ & $\$ 12,796,080$ & $\$ 256,446,773$ \\
\hline Person & 11,736 & 4883 & $\$ 1,924,668$ & $\$ 297,610,614$ & $\$ 17,119,080$ & $\$ 316,654,362$ \\
\hline \multicolumn{7}{|l|}{ Age 15-24 } \\
\hline Female & 5267 & 2110 & $\$ 797,084$ & $\$ 93,642,104$ & $\$ 7,089,720$ & $\$ 101,528,908$ \\
\hline Male & 13,477 & 5759 & $\$ 2,187,123$ & $\$ 384,294,347$ & $\$ 19,453,500$ & $\$ 405,934,970$ \\
\hline Persons & 18,744 & 7869 & $\$ 2,984,207$ & $\$ 481,580,670$ & $\$ 26,543,220$ & $\$ 511,108,097$ \\
\hline
\end{tabular}

Table 5 considers the cost by means of suicide. Threat to breathing, including hanging, suffocation by putting a plastic bag or pillow over one's head, and intentional drowning, accounted for more than 14,105 YLL and more than \$384.6 million of the total cost of suicide. Blunt force, such as jumping from a height, person moving in front of a moving object, such as a train or motor vehicle, and motor vehicle crash, was the second largest method of suicide among youth accounting for 2195 YLL and $\$ 59.9$ million. Piercing and penetrating force, including shooting with firearms and stabbing with a knife or other sharp instruments, claimed 907 YLL and just under \$25 million of the total cost of suicide in 2014.

Table 5. The total economic cost of youth suicide, Australia, 2014, by means of suicide.

\begin{tabular}{|c|c|c|c|c|c|c|}
\hline \multirow{2}{*}{ Variable } & \multirow{2}{*}{$\begin{array}{l}\text { Years of } \\
\text { Life Lost }\end{array}$} & \multirow{2}{*}{$\begin{array}{l}\text { Year of Productive } \\
\text { Life Lost }\end{array}$} & \multicolumn{3}{|c|}{ Economic Cost (AU\$) } & \multirow{2}{*}{ Total } \\
\hline & & & Direct & Indirect & Intangible & \\
\hline Threat to breathing & 14,105 & 5921 & $\$ 2,245,446$ & $\$ 362,362,002$ & $\$ 19,972,260$ & $\$ 384,579,708$ \\
\hline Blunt force & 2195 & 923 & $\$ 349,940$ & $\$ 56,472,000$ & $\$ 3,112,560$ & $\$ 59,934,500$ \\
\hline Exposure to chemical or other substance & 1357 & 564 & $\$ 213,852$ & $\$ 34,510,667$ & $\$ 1,902,120$ & $\$ 36,626,639$ \\
\hline Piercing, penetrating force & 907 & 384 & $\$ 145,808$ & $\$ 23,530,000$ & $\$ 1,296,900$ & $\$ 24,972,708$ \\
\hline Other & 180 & 77 & $\$ 29,162$ & $\$ 4,706,000$ & $\$ 259,380$ & $\$ 4,994,542$ \\
\hline Total & 18,744 & 7869 & $\$ 2,984,207$ & $\$ 481,580,670$ & $\$ 26,543,220$ & $\$ 511,108,097$ \\
\hline
\end{tabular}




\subsection{Sensitivity Analysis}

Table 6 provides results of the sensitivity analysis. The baseline cost of suicide of $\$ 511.1$ million ranged between $\$ 460.0$ and $\$ 585.9$ million. The largest deviation related to the proportion of youth being employed (Sensitivity 5 ) and the theoretically reduced number of suicides per year (Sensitivity 1 ). For example, a reduction in youth suicides by $10 \%$ could potentially alleviate the economic burden by up to $\$ 51.1$ million per year including $\$ 298,421$ (\$0.3 million) in direct costs, $\$ 2.7$ million as intangible, and $\$ 48.2$ million as indirect costs.

Table 6. Sensitivity analysis of key parameters (in AU\$).

\begin{tabular}{cc}
\hline Parameter Varied & Total Cost of Youth Suicide (AU\$) \\
\hline Number of suicides & \\
\hline Sensitivity $1=276$ (reduction by 10\%) & $\$ 459,997,288$ \\
Sensitivity $2=292$ (reduction by $5 \%$ ) & $\$ 485,552,692$ \\
Sensitivity $3=304$ (reduction by 1\%) & $\$ 505,997,016$ \\
Baseline $=307$ & $\$ 511,108,097$ \\
\hline Average weekly earnings & \\
\hline Baseline $=\$ 911$ (Female); $\$ 1363$ (Male); $\$ 1251$ (Person) & $\$ 511,108,097$ \\
Sensitivity $4=\$ 940$ (Female); $\$ 1430($ Male); $\$ 1302$ (Person) & $\$ 530,651,954$ \\
\hline Proportion of youth that employed & \\
\hline Baseline $=56 \%$ & $\$ 511,108,097$ \\
\hline Sensitivity $5=65 \%$ & $\$ 585,921,731$ \\
\hline Funeral cost & \\
\hline Baseline $=4000$ & $\$ 511,108,097$ \\
\hline Sensitivity $6=15,000$ & $\$ 514,485,097$ \\
\hline Sensitivity $7=4 \%$ & \\
\hline Baseline $=4.58 \%$ & $\$ 580,352,099$ \\
\hline Sensitivity $8=5 \%$ & $\$ 511,108,097$ \\
\hline
\end{tabular}

\section{Discussion}

The economic cost of youth suicide in Australia is estimated at $\$ 511$ million a year (\$460-586 million) in 2014 AU\$. Direct costs account for $\$ 3$ million (1\% of the total cost); indirect costs at $\$ 482$ million (94\%); and intangible costs at \$27 million (5\%).

The cost of suicide increases by age cohort, from $\$ 192$ million (for 15-19-year-olds) to $\$ 317$ million (for 20-24-year-olds). This increase is attributable to the higher prevalence of suicide among 20-24-year-olds (12.0 per 100,000) compared to 15-19-year-olds (7.4 per 100,000). It is also worth noting that the cost of male youth suicide is significantly higher than the cost of female suicide (\$406 million versus $\$ 102$ million, respectively), again due to higher prevalence of suicide deaths in the former group (14.0 versus 5.4 per 100,000 population, respectively). Threats to breathing are the most common cause of death regardless of the age or gender and account for over $\$ 385$ million (75\%) of the estimated total cost.

Although the effectiveness of this approach is yet to be established, our findings suggest that the impact of meeting a $10 \%$ reduction in youth suicide could potentially save many lives and over $\$ 51$ million a year, including \$298,421 (\$0.3 million) in direct costs, \$3 million as intangible and $\$ 48$ million as indirect costs.

\section{Conclusions}

An average of 319 young Australians take their lives each year at an economic cost of $\$ 511$ million. 


\section{Other Corrections:}

In Table 1, the average weekly earnings for females were $\$ 940$ and for males- $\$ 1430$.

Reference 19 should read:

19 Doran, C.M.; Ling, R.; Milner, A.; Kinchin, I. The Economic Cost of Suicide and Non-Fatal Suicidal Behaviour in the Australian Construction Industry. Int. J. Ment. Health Psychiatry 2016, 2, doi:10.4172/2471-4372.1000130.

\section{References}

1. Kinchin, I.; Doran, C.M. The Cost of Youth Suicide in Australia. Int. J. Environ. Res. Public Health 2018, 15, 672. [CrossRef] [PubMed]

(C) 2018 by the authors. Licensee MDPI, Basel, Switzerland. This article is an open access article distributed under the terms and conditions of the Creative Commons Attribution (CC BY) license (http://creativecommons.org/licenses/by/4.0/). 